\title{
Gender Differences in Within-Year Changes in Motivation and Achievement in Mathematics
}

\author{
Wondimu Ahmed ${ }^{1}$ \\ ${ }^{1}$ The University of Akron, Akron, OH, USA \\ Correspondence: Wondimu Ahmed, Department of Educational Foundations and Leadership, The LeBron James \\ Family Foundation College of Education, The University of Akron, Akron, OH, 44325-4208, USA. Tel: \\ 1-330-972-6771. E-mail: wahmed@uakron.edu
}

Received: August 14, 2015

doi:10.5539/jedp.v6n1p95

\author{
Accepted: December 10, $2015 \quad$ Online Published: February 2, 2016 \\ URL: http://dx.doi.org/10.5539/jedp.v6n1p95
}

\begin{abstract}
This study examined gender differences in the longitudinal associations between changes in motivation and achievement in mathematics in a sample of 495 early adolescents (51\% girls). Growth curve analyses indicated that gender did not have a significant effect on both initial levels of and rates of change in self-concept and achievement. However, gender had a significant effect on the rates of change in intrinsic value such that girls showed a slower rate of decline than boys. The analyses also indicated that the associations between motivation and achievement are stronger for boys than for girls. This suggests that the decline in motivation overtime is more likely to negatively impact boys' achievement than that of girls'.
\end{abstract}

Keywords: motivational beliefs, mathematics achievement, gender differences, growth curve analysis

\section{Introduction}

Although recent meta-analytic reviews of gender differences in mathematics performance seem to suggest that the gender gap is narrowing (e.g., Lindenberg, Hyde, \& Peterson, 2010; Stoet \& Geary, 2012) gender differences in motivation in this domain continue to be reported (e.g., Else-Quest, Hyde, \& Linn, 2010; Meece, Glienke, \& Burg, 2006). Because motivation is an important predictor of academic achievement, even when intelligence is taken into account (Steinmayr \& Spinath, 2009), there is an increasing interest in examining whether gender differences in motivation impact students' achievement (Simpkins \& Davis-Kean, 2005; Watt, 2004). Although, a great of deal of research has been conducted on the issue of gender differences in motivation (see Meece et al., 2006 for a review), we know little about whether gender differences in motivation translate into gender differences in outcomes (Meece et al., 2006). Much of the previous longitudinal studies focused on comparing mean level gender differences in motivational beliefs. These types of studies are helpful in providing a longitudinal changes in students' motivation, however, they do not provide us with any information regarding gendered motivational processes (Watt, 2004). Moreover, much of the longitudinal research to date has focused on year-to-year changes although evidence indicates that achievement motivation shows higher within-year changes than between-year changes (Bong, 2005; Meece \& Miller, 2001). Whereas within-year changes are more likely to reflect true school experiences during the academic year, year-to-year changes are confounded by transitions, changes in curriculum, tracking polices and the like (Meece \& Miller, 2001). This study attempted to address such limitations in the literature. More specifically, the objective of this study was twofold (a) to examine whether gender predicts growth trajectories of motivational beliefs and achievement, and (b) to investigate whether there are gender differences in the associations between the trajectories of motivation and that of achievement.

\subsection{Theoretical Framework}

A prominent theoretical model that has been widely used to investigate gender differences in motivation and achievement is the Expectancy-Value Theory (EVT) (Eccles, Adler, Futterman, Goff , Kaczala, \& Meece,1983; Wigfield \& Eccles, 2000). According to EVT, expectancies and values are the most immediate predictors of performance, persistence and task choice. Eccles and colleagues (1983) defined expectancies as beliefs about how well one will perform on an upcoming task. Although expectancies are theoretically distinct from self-concept of ability which is defined as children's evaluation of their competence in a task, empirical evidence shows that both children and adolescents do not distinguish between the two constructs (Eccles \& Wigfield, 1995). Thus, 
self-concept of ability is commonly used to operationalize the expectancy component of EVT. Eccles and colleagues (1983) proposed four components of achievement value: attainment value, intrinsic value, utility value and cost (e.g., Eccles, 2009; Eccles et al., 1983; Wigfield \& Eccles, 1992, 2000). Attainment value refers to the perceived importance of doing well on a task. Intrinsic value of a task refers to the enjoyment one experiences by engaging in the task. Utility value is the perception of how a task fulfills an individuals' future plans. The cost component refers to lost opportunities as a result of engaging in one task rather than the other. Most of the research to date has focused on the first three components of value. The present study focused on intrinsic value component of achievement value because constructs akin to this component such as interest and intrinsic motivation have been shown to impact learning and performance (Hidi, 2006; Hidi \& Ainley, 2007; Ryan \& Deci, 2000). Moreover, research shows that girls and boys differ in intrinsic value of math but not utility value of math (e.g., Frenzel, Goetz, Pekrun, \& Watt, 2010; Watt, 2004). The theory hypothesizes that both expectancies and values are influenced by, among others, self-concept of ability, perceived task difficulty and self-schemas; which are in turn influenced by perceptions of other people's attitudes and expectations as well as children's own interpretations of their prior achievement outcomes. The expectations and perceptions themselves are influenced by a variety of social, psychological and cultural factors.

In support of the EVT, several meta-analyses (e.g., Huang, 2011; Möller, Pohlmann, Köller, \& Marsh, 2009; Valentine, DuBois, \& Cooper, 2004) have shown that self-concept of ability (here after self-concept) is substantially associated academic achievement. For instance, Möller et al.'s (2009) meta-analysis showed that within domain correlations between self-concept and achievement are stronger than that of between domain correlations. For example, whereas their meta-analysis revealed a mean correlation of .43 between math self-concept and math achievement, the average correlation between verbal self-concept and math achievement was .12. More recently, Huang's (211) meta-analysis of 32 longitudinal studies showed that correlations between prior self-concept and subsequent achievement were in the range of 0.24 and 0.25 .

With regard to value, much of the research to date has focused on examining the link between task value and intentions or actual course-taking decisions. This body of research generally shows that subjective task value predicts both intentions and actual choices of courses and careers (for a review see Eccles \& Wigfield, 2002). A limited number of studies have also shown the importance of task value for achievement. For instance, Steinmayr and Spinath (2009) found that both self-concept and task value had incremental validity over general intelligence, math intelligence and verbal intelligence in predicting school achievement. One limitation of the previous studies that have examined the link between task value and achievement is that most of them used composite measure of value (i.e., sum of intrinsic value, attainment value $\&$ utility value). Although an omnibus measure is pragmatic, the use of such measures masks the differential contribution of each of the components of achievement value (Wigfield, Hoa, \& Claudia, 2010). This is important given the evidence that the components are distinct (Eccles \& Wigfield, 1995) and that they follow different developmental trajectories (Watt, 2004).

The EVT further proposes that individual and group differences in the motivational beliefs arise from several psychological, social and cultural influences. Among others, the theory proposes gender differences in the motivational beliefs (i.e., self-concept and value) are more likely to derive from differential socialization patterns at home and the school. Eccles and colleagues argue that this is particularly true in gender-role stereotyped domains such as math and languages. As girls and boys are socialized differently in to these domains, they quickly come to judge their ability to engage in and their values of such activities in line with the stereotypes. Consistent with this notion, a number of studies have shown that females score lower than males on self-reported measures of ability. For example, over the last four decades studies have consistently shown that girls report lower self-concept of math ability than boys, and particularly so during adolescence. In most cross-sectional studies, boys report significantly higher self-concept in mathematics than girls (e.g., Eccles et al., 1993; Else-Quest et al., 2010; Marsh \& Yeung, 1998; Meece et al., 2006). Longitudinal studies on gender differences in the development of self-concept are inconsistent. While some studies documented no gender differences in changes in self-concept of ability (Eccles, Midgley, \& Adler, 1984), other studies (e.g., Wigfield et al., 1997; Ruble \& Martin, 1998) report increases in gender differences in self-concept of ability in middle childhood and adolescence. Some recent studies however show that gender differences in development decrease but not increase overtime (Jacobs, Lanza, Osgood, Eccles, \& Wigfield, 2002).

Compared with the work on gender differences in self-concept, there has been less research on gender differences in task value. What available evidence is inconsistent. Whereas a number of studies have shown that females report lower intrinsic value of math (e.g., Frenzel et al., 2010; Watt, 2004) other studies have found no gender differences in the subjective value of math (Jacobs et al., 2002) (for a review see Meece et al., 2006). Much of the previous 
research on motivation focused on mean level differences in self-concept and achievement value between males and females. Although examination of mean level differences helps in mapping the development of motivation among males and females, it can not provide us with information on how different types of motivational constructs operate across genders (Eccles, 2009). The study of the development of motivation is crucial to help us design appropriate motivational interventions at various stages of students' educational careers. Knowledge of how different motivational process operate across different groups would be ultimately useful for designing interventions that target the specific groups (e.g., females vs. males) so that modification can be made as needed. This type of knowledge could only be obtained by examining patterns of group differences in the relationship between motivation and achievement.

The present study attempts to fill this gap in the literature. Although a number of studies have documented declining trends for achievement motivation, only a few have examined whether girls and boys follow different developmental trajectories. In addition, much of the previous research focused on grade or age-related changes in motivation. Although such studies are useful in discerning the ontogeny of motivation, they are confounded by a number of factors such as tracking policy and transitions (Meece \& Miller, 2001). Within-year or within-grade changes in motivation reflect students' experiences within an academic year. The changes may come about as a result of changes in the classroom climate as well as evaluative feedback from teachers. Moreover, most of the previous research used omnibus measure of achievement value without making distinctions between the components. As mentioned above, the current study focused on intrinsic value. The objective of the current study was twofold (a) to examine whether gender predicts the initial levels and rate of changes in motivational beliefs and achievement, (b) to investigate whether correlations between growth parameters of motivation and of achievement in math differ for boys and girls.

\section{Method}

\subsection{Participants and Procedure}

The data for the current study are taken from a longitudinal project aimed at investigating changes in emotions, motivation and self-regulated learning among young adolescents (see Ahmed, Minnaert, van der Werf, \& Kuyper, 2012; Ahmed, van der Werf, Kuyper, \& Minnaert, 2013). The participants were 495 early adolescents attending two secondary schools located in two upper middle-income suburban communities in the Netherlands. Fifty-one percent of the participants were girls. Informed written consent was obtained from parents or guardians. Participants were informed of their freedom to discontinue participation at any time and of the confidentiality of the study. The participants provided data at three occasions: at the beginning (T1), in the middle (T2) and at the end (T3) of the 2007/2008 school year.

\subsection{Measures}

\subsubsection{Motivational Beliefs}

The motivational beliefs measures (i.e., self-concept and intrinsic value) were adapted from Wigfield and Eccles (2000). Both measures were rated on a 5-point Likert type scale, ranging from 1 to 5 .

\section{(1) Self-concept}

The self-concept measure (4 items) assessed among others how good the participants thought they were at math was, how well they expected to do well in the future in math, and how good they thought they would be at learning something new in math. An example item is "How good at math are you?" $(1=$ not at all good, $5=$ very good $)$. The internal consistencies across all three waves in the present sample were adequate $(\alpha=.84, .88$, and .88 , respectively).

\section{(2) Intrinsic Value}

The intrinsic value scale ( 2 items) assessed students' level of enjoyment of and interest in mathematics. An example item is: "How much do you like doing math?" $(1=$ not at all, $5=$ very $m u c h)$. The internal consistencies across all three waves in the present sample were adequate $(\alpha=.83, .87$, and .84 , respectively).

\subsubsection{Mathematics Achievement}

The researcher collected the participants' math grades for the three trimesters of the 2007/2008 academic year from the school record office. The grading scale ranges from 1 (poor) to 10 (outstanding). 


\subsection{Analytic Strategy}

Data were analyzed using growth curve modeling within multilevel framework (Snijders \& Bosker, 2012; Singer $\&$ Willet, 2003). The current data are clustered because measurements are nested within individual participants. In order to examine the effect of gender on the simultaneous growth trajectories of the motivational beliefs and achievement, a multivariate growth curve modeling was used. A Multivariate GC (MGC) is helpful in modeling parallel growth in outcome variables of interest (Steele, 2008). The analyses preceded in a series of steps. First, an unconditional MGC model was fitted to describe the general growth trajectories of the motivational beliefs and of achievement. Second gender $(0=$ female, $1=$ male $)$ was added to the model as a time-invariant predictor. Third, two MGC models were tested to examine the associations between growth parameters of the five variables for boys and girls separately. Fourth, the covariances between the growth parameters were converted to correlations and Fisher r-to-z transformation was used to test the significance of the differences between the correlations for boys and girls. Fisher r-to-z transformation is important to test whether two independent correlations significantly different from each other (Kenny, 1979). Model fit was assessed by comparing nested models and deviance statistics. Because deviance is a measure of lack of fit, only comparison of deviance of two nested models is used to determine if one model fits the data better than the other. The difference in deviance has a chi-square with degree of freedom equal the difference in the number of free parameters (Snijder \& Bosker, 2012). All models were tested using the software program MLwIN 2.26 (Rasbash, Steele, Browne, \& Goldstein, 2012) and using maximum likelihood estimation.

\section{Results}

Table 1 presents the descriptive statistics (means and standard deviations) of the study variables. The raw data indicate a decreasing trend for the two motivational variables and achievement.

Table 1. Means and standard deviations for motivational beliefs and achievement for the three measurement occasions

\begin{tabular}{lllllll}
\hline & \multicolumn{3}{c}{ Boys } & \multicolumn{3}{c}{ Girls } \\
\cline { 2 - 7 } & Time 1 & Time 2 & Time 3 & Time 1 & Time 2 & Time 3 \\
\hline Self-concept & $3.49(.57)$ & $3.35(.70)$ & $3.26(.72)$ & $3.38(.62)$ & $3.282(.69)$ & $3.07(.81)$ \\
Intrinsic value & $3.29(.81)$ & $2.95(.88)$ & $2.66(.86)$ & $3.20(.75)$ & $2.91(.79)$ & $2.74(.83)$ \\
Achievement & $7.07(1.15)$ & $6.77(1.15)$ & $6.53(1.22)$ & $7.18(1.14)$ & $6.90(1.21)$ & $6.76(1.17)$ \\
\hline
\end{tabular}

Compared to the unconditional means model, the unconditional growth model fitted the data very well $\left(\chi^{2}=\right.$ $365.16, \mathrm{p}<.01 ; \mathrm{df}=18$ ). Mean initial levels (intercepts) of self-concept, intrinsic value and achievement were $3.55,3.40$ and 7.20 respectively. The rates of change (slopes) in the self-concept, intrinsic value and achievement were $-.14,-.28$ and -.25 , respectively $(p$ 's $<.01)$. That these parameter estimates are negative and significant indicates that, on average, the students experienced significant linear decrease in motivation and achievement over the course of the study. There were significant individual differences in the rate of change in self-concept, intrinsic value and achievement $(p$ 's $<.01)$. Thus, while the motivational variables and achievement showed a decreasing trend on average, there were differences in the individual trajectories experienced by different students.

Next, gender was added to the unconditional MGC model. This conditional model, in comparison with the unconditional growth model, fitted the data well: $\chi^{2}=31.12, \mathrm{p}<.01$; $\mathrm{df}=3$. Table 2 presents the multilevel regression estimates for each of the motivational variables and achievement. The table shows that gender was a significant predictor of intrinsic value slope $(p<.05)$. This suggests that girls demonstrated a slow rate of change in intrinsic value compared to boys. All other coefficients were not statistically significant. 
Table 2. Effect of gender on growth parameters of motivational beliefs and achievement

\begin{tabular}{lccl}
\hline & $\mathrm{B}$ & $\mathrm{T}$ & $95 \% \mathrm{CIs}$ \\
\hline 1. Self-concept intercept & .05 & 1.83 & $(-.00, .10)$ \\
2. Self-concept slope & .02 & 1.30 & $(-.01, .05)$ \\
3. Intrinsic value intercept & .05 & 1.43 & $(-.02, .11)$ \\
4. Intrinsic value slope & -.06 & $-2.15^{*}$ & $(-.08,-.00)$ \\
5. Achievement intercept & -05 & -1.03 & $(-.15, .05)$ \\
6. Achievement slope & -.03 & -1.10 & $(-.07, .02)$ \\
\hline
\end{tabular}

$* p<.05$

In the third step, two MGC models were fitted to girls and boys data separately. Before growth curve models were ran, the researcher tested an unconditional means model for boys and girls separately. These unconditional models were used to examine the fit of the growth curve model. The models demonstrated good fit to the data compared to their respective unconditional means models (girls' data, $\chi^{2}=201.28, \mathrm{p}<.01 ; \mathrm{df}=18$ ) and (boys' data, $\chi^{2}=$ $227.64, \mathrm{p}<.01 ; \mathrm{df}=18$ ). Table 3 presents the correlations between growth parameters of motivation variables and that of achievement for boys and girls. The z-scores indicate that the correlations between changes in motivation and changes in achievement are stronger for boys than for girls. Thus, the decline in motivation observed in this study seems to impact the boys' achievement more than that of the girls'.

Table 3. Correlations between growth parameters (intercepts and slopes) of motivational beliefs and achievement in math for boys and girls

\begin{tabular}{lllllll}
\hline & \multicolumn{7}{l}{ Achievement intercept } & \multicolumn{3}{l}{ Achievement slope } \\
\hline & Girls & Boys & $\mathrm{Z}$ & Girls & Boys & $\mathrm{Z}$ \\
\hline 1. Self-concept intercept & $.76^{* *}$ & $.78^{* *}$ & -.54 & .12 & .53 & $-4.17^{* *}$ \\
2. Self-concept slope & $.21^{*}$ & .04 & -1.92 & $.65^{* *}$ & $.76^{* *}$ & $-2.44^{*}$ \\
3. Intrinsic value intercept & $.19^{*}$ & $.50^{* *}$ & $-3.95^{* *}$ & .03 & $.21^{*}$ & $-2.02^{*}$ \\
4. Intrinsic value slope & .07 & $.35^{* *}$ & $-3.25^{* *}$ & .13 & $.74^{* *}$ & $-9.06^{* *}$ \\
\hline
\end{tabular}

$* p<.05, * * p<.01$

\section{Discussion}

The objective of the current study was twofold (a) to examine whether gender predicts growth trajectories of motivation and achievement, and (b) to investigate whether correlations between growth trajectories of motivation and of achievement in math differ for boys and girls. The findings showed that gender predicted the rates of change in intrinsic value and that the associations between trajectories of the motivation and of achievement differ between boys and girls.

A large body of the literature on the development of motivation shows that students' motivation declines with age (e.g., Fredricks \& Eccles, 2002; Jacob et al., 2002; Watt, 2004; Wigfield \& Eccles, 2002). Consistent with this body of the literature, the finding of the current study showed that students' motivation declined over the course of the study. Much of the previous developmental research emphasized year-to-year changes in motivation. The findings of the current study showed that motivation decreased in the course of a year. Such short-term changes in motivation demonstrate that even when teachers and curricula do not change; students' motivation may decline over time (Meece \& Miller, 2001). Previous studies that followed students for a fairly long period of time explained declines in motivation in terms of cognitive development and stage-environment fit (Eccles, 1992; Eccles, 2004; Wigfield \& Eccles, 2002). Whereas the cognitive developmental hypothesis posits that as children mature their self-evaluations tend to match reality and thus declines are more likely to be the norm, the stage-environment fit explanation suggests that as children move from elementary to middle/high school they experience a school transition that is inappropriate for maintaining motivation. According to the latter view, the 
declines in motivation occur as result of school structural changes. The findings of the current study show that even within a single year, students' motivation shows a declining pattern. Whereas this finding is troubling, it also suggests that the social context of the classroom are more likely to be the source influence of the motivational changes because the curriculum and teacher were kept intact.

Research over the last two decades has shown that females generally report lower self-concept and lower intrinsic value of mathematics (for reviews see Meece et al., 2006; Else-Quest et al., 2010). Contrary to the findings of a large number of studies, gender was not found to be a significant predictor of initial levels or rates of change in self-concept. Boys and girls were at the same level when they started participating in this study and the rate at which their self-concept declined did not differ from each other. Similarly, boys and girls did not differ in the initial levels of intrinsic value but girls showed a slower rate of decline in this construct. There was non-significant difference between boys and girls with regard to the initial levels and rates of changes in achievement. This is rather surprising given a number of numerous cross-sectional studies that showed significant differences between boys and girls in the motivation and achievement (see Lindenberg et al., 2010; Stoet \& Geary, 2012 for review).

The MGC models fitted to the girls' and boys' data generally showed that there are both differences and similarities in the correlations between growth parameters of motivation and achievement for boys and girls. Although the correlation between initial levels of self-concept and initial levels of achievement did not differ across gender, the correlations between the rates of change in both variables demonstrated significant difference. More specifically, consistent with previous cross-sectional studies (e.g., Eccles et al., 1993) the findings showed that the correlations between the rates of changes in self-concept and the rate of changes in achievement are stronger for boys than for girls. With regard to the link between intrinsic value and achievement, both the correlations between the initial levels as well as the rates of changes differed significantly. More specifically, the correlations between initial levels of intrinsic value and achievement were stronger for boys than for girls. Similarly, correlations between rates of change in intrinsic value and achievement were stronger for boys than for girls. The results should however be interpreted with caution, some of the correlations are not at all significant to make meaningful comparison. Overall, these patterns of findings show that the decline in motivation observed in the current study is more likely to negatively influence boys' achievement than girls' achievement. The findings of the current study may reflect gendered motivational processes that, in turn, reflect how girls and boys interpret their math classrooms (Eccles, 2005).

There are several limitations to this study. First, this study used self-report to measure students' motivational beliefs. Although self-reports are the most common assessment tools in the motivation literature, the emerging body of evidence suggests that self-beliefs may or may not reflect actual abilities or attitudes (Hacker, Bol, \& Keener, 2008). Studies also show that girls are more accurate than boys in terms of perception of ability (Boekaerts \& Rozendaal, 2010). Thus, future research should use implicit measures of motivation to discern gendered patterns of influences on achievement. Second, the study was inherently based on the assumption that gender differences in students' motivational beliefs can be influenced by the stereotypes they hold regarding the gender appropriateness of mathematics (Wigfield \& Eccles, 2000). Although stereotype may partly be responsible for differences in the motivational beliefs, the current study did not consider such variables. Future research should examine how stereotypical beliefs and motivational beliefs as well as achievement change over time. Third, the current study did not assess the classroom climate that might have precipitated the declines in motivation and achievement. Understanding the social-emotional climate of the math classroom might provide us with a clear picture of why and how changes in both motivation and achievement occur. Finally, this study focused on mathematics. Math is a male stereotyped domain. Thus, using this domain to examine within-year changes in motivation and achievement during early adolescence helps in revealing potential challenges that students may experience at this crucial developmental stage where identity for careers begin to take shape. Yet, it is important to recognize that other domains, particularly, language needs to be carefully examined in this regard as the there is a mounting evidence that boys are consistently underperforming in this domain.

\section{References}

Ahmed, W., Minnaert, A., van der Werf, G., \& Kuyper, H. (2012). Reciprocal relationships between math self-concept and math anxiety. Learning and Individual Differences, 22, 385-389. http://dx.doi.org/10.1016/j.lindif.2011.12.004

Ahmed, W., van der Werf, G., Kuyper, H., \& Minnaert, A. (2013). Emotions, self-regulated learning, and achievement in mathematics: A growth curve analysis. Journal of Educational Psychology, 105(1), 150-161. http://dx.doi.org/10.1037/a0030160 
Bong, M. (2005). Within-grade changes in Korean girls' motivation and perceptions of the learning environment across domains and achievement levels. Journal of Educational Psychology, 97, 656-672.

Boekaerts, M., \& Rozendaal, J. (2010). Using multiple calibration indices in order to capture the complex picture of what affects students' accuracy of feeling of confidence. Learning and Instruction, 20(5), 372-382. http://dx.doi.org/10.1016/j.learninstruc.2009.03.002

Eccles, J. S. (1992). School and family effects on the ontogeny of children's interests, self-perceptions, and activity choices. Nebraska Symposium on Motivation, 40, 145-207.

Eccles, J. S. (2004). Schools, academic motivation, and stage-environment fit. In R. M. Lerner, \& L. Steinberg (Eds.), Handbook of adolescent psychology (2nd ed., pp. 125-153). New York: John Wiley and sons. http://dx.doi.org/10.1002/9780471726746.ch5

Eccles, J. S. (2005). Studying gender and ethnic differences in participation in math, physical science, and information technology. New Directions in Child and Adolescent Development, 110, 7-14. http://dx.doi.org/10.1002/cd.146

Eccles, J. (2009). Who am I and what am I going to do with my life? Personal and collective identities as motivators of action. Educational Psychologist, 44, 78-89. http://dx.doi.org/10.1080/00461520902832368

Eccles, J., Adler, T. F., Futterman, R., Goff, S. B., Kaczala, C. M., Meece, J. L., \& Midgley, C. (1983). Expectancies, values, and academic behaviors. In J. T. Spence (Ed.), Achievement and achievement motivation: Psychological and sociological approaches (pp. 75-146). San Francisco, CA: Freeman.

Eccles, J., Midgley, C., \& Adler, T. (1984). Grade-related changes in the school environment: Effects on achievement motivation. In J. Nichols (Ed.), The development of achievement motivation (Vol. 3, pp. 283-331). Greenwich, CT: JAI Press.

Eccles, J., Midgley, C., Wigfield, A., Buchanan, C., Reuman, D., Flanagan, C., \& MacIver. D. (1993). Development during adolescence: The impact of stage - environment fit on young adolescents' experiences in schools and families. American Psychologist, 48, 90-101.

Eccles, J. S., \& Wigfield, A. (1995). In the mind of the achiever: The structure of adolescents' academic achievement related-beliefs and self-perceptions. Personality and Social Psychology Bulletin, 21, 215-225. http://dx.doi.org/10.1177/0146167295213003

Eccles, J. S., \& Wigfield, A. (2002). Motivational beliefs, values, and goals. Annual Review of Psychology, 53, 109-132. http://dx.doi.org/10.1146/annurev.psych.53.100901.135153

Else-Quest, N. M., Hyde, J. S., \& Linn, M. C. (2010). Cross-national patterns of gender differences in mathematics achievement, attitudes, \& affect: A meta-analysis. Psychological Bulletin, 136, 103-127.

Fredricks, J. A., \& Eccles, J. (2002). Children's competence and value beliefs from childhood through adolescence: Growth trajectories in two male-sex-typed domains. Developmental Psychology, 38, 519-533. http://dx.doi.org/10.1037/0012-1649.38.4.519

Frenzel, A. C., Goetz, T., Pekrun, R., \& Watt, H. M. G. (2010). Development of mathematics interest in adolescence: Influences of gender, family, and school context. Journal of Research on Adolescence, 20, 507-537. http://dx.doi.org/10.1111/j.1532-7795.2010.00645.x

Jacobs, J. E., Lanza, S., Osgood, D. W., Eccles, J. S., \& Wigfield, A. (2002). Changes in children's self-competence and values: Gender and domain differences across grades one through twelve. Child Development, 73, 509-527. http://dx.doi.org/10.1111/1467-8624.00421

Hacker, D., Bol, L., \& Keener, M. (2008). Metacognition in education: A focus on calibration. In J. Dunlosky, \& R. Bjork (Eds.), Handbook of memory and metacognition (pp. 429-455). Mahwah, New Jersey: Lawrence Erlbaum Associates.

Hidi, S. (2006). Interest: A unique motivational variable. Educational Research Review, 1(2), 69-82.

Hidi, S., \& Ainley, M. (2007). Interest and self-regulation: Relationships between two variables that influence learning. In B. J. Zimmerman, \& D. H. Schunk (Eds.), Motivation and self-regulated learning: Theory, research, and applications (pp. 77-109). Mahwah, NJ: Erlbaum.

Huang, C. (2011). Self-concept and academic achievement: A meta-analysis of longitudinal relations. Journal of School Psychology, 49, 505-528. 
Kenny, D. A. (1979). Correlation and Causality. New York: Wiley-Interscience.

Lindberg, S. M., Hyde, J. S., Petersen, J. L., \& Linn, M. C. (2010). New trends in gender and mathematics performance: A meta-analysis. Psychological Bulletin, 136, 1123-1135. http://dx.doi.org/10.1037/a0021276

Marsh, H. W., \& Yeung, A. S. (1997). Causal effects of academic self-concept on academic achievement: Structural equation models of longitudinal data. Journal of Educational Psychology, 89, 41-54.

Meece, J. L., Glienke, B. W., \& Burg, S. (2006). Gender and motivation. Journal of School Psychology, 44, 351-373. http://dx.doi.org/10.1002/cd.145

Meece, J. L., \& Miller, S. D. (2001). A longitudinal analysis of elementary school students' achievement goals in literacy activities. Contemporary Educational Psychology, 26, 454-480. http://dx.doi.org/10.1006/ceps.2000.1071

Möller, J., Pohlmann, B., Köller, O., \& Marsh, H. W. (2009). A meta-analytic path analysis of the internal/external frame of reference model of academic achievement and academic self-concept. Review of Educational Research, 79, 1129-1167. http://dx.doi.org/10.3102/0034654309337522.

Rasbash, J., Steele, E., Browne, W. J., \& Prosser, B. (2012). A User's Guide to MLwiN (version 2.31). Bristol: University of Bristol.

Ruble, D. N., \& Martin, C. L. (1998). Gender development. In W. Damon, \& N. Eisenberg (Eds.), Social, emotional, and personality development (pp. 933-1016). New York: Wiley.

Ryan, R. M., \& Deci, E. L. (2000). Self-determination theory and the facilitation of intrinsic motivation, social $\begin{array}{llll}\text { development, and } \quad \text { well-being. } & \text { American }\end{array}$ http://dx.doi.org/10.1037/0003-066X.55.1.68

Simpkins, S. D., \& Davis-Kean, P. E. (2005). The intersection between self-concepts and values: Links between beliefs and choices in high school. New Directions for Child and Adolescent Development, 110, 31-47. http://dx.doi.org/10.1002/cd.148

Singer, J. D., \& Willet, J. B. (2003). Applied longitudinal data analysis: Modeling change and event occurence. http://dx.doi.org/10.1093/acprof:oso/9780195152968.001.0001

Snijders, T. A. B., \& Bosker, R. J. (2012). Multilevel analysis: An introduction to basic and advanced multilevel modeling (2nd ed.). Thousand Oaks, CA: Sage.

Steele, F. (2008). Multilevel Models for Longitudinal Data. Journal of the Royal Statistical Society. Series A (Statistics in Society), 171, 5-19.

Steinmayr, R., \& Spinath, B. (2009). The importance of motivation as a predictor of school achievement. Learning and Individual Differences, 19(1), 80-90.

Valentine, J. C., DuBois, D. L., \& Cooper, H. (2004). The relation between self-beliefs and academic achievement: A meta-analytic review. Educational Psychologist, 39, 111-123. http://dx.doi.org/10.1207/s15326985ep3902_3

Watt, H. M. G. (2004). Development of adolescents' self-perceptions, values and task perceptions according to gender and domain in $7^{\text {th }}$ through 11th-grade Australian students. Child Development, 75, 1556-1574. $\mathrm{http}: / / \mathrm{dx}$. doi.org/10.1111/j.1467-8624.2004.00757.x

Wigfield, A., \& Eccles, J. (1992). The development of achievement task values: A theoretical analysis. Developmental Review, 12, 265-310. http://dx.doi.org/10.1016/0273-2297(92)90011-P

Wigfield, A., \& Eccles, J. S. (2000). Expectancy-value theory of achievement motivation. Contemporary Educational Psychology, 25, 68-81. http://dx.doi.org/10.1006/ceps.1999.1015

Wigfield, A., \& Eccles, J. S. (2002). The development of competence beliefs and values from childhood through adolescence. In A. Wigfield, \& J. S. Eccles (Eds.), Development of achievement motivation (pp. 91-120). San Diego, CA: Academic Press. http://dx.doi.org/10.1016/B978-012750053-9/50006-1

Wigfield, A., Eccles, J. S., Yoon, K. S., Harold, R. D., Arbreton, A. J. A., Freedman-Doan, C. R., \& Blumenfeld, P. C. (1997). Change in children's competence beliefs and subjective task values in and across the elementary $\begin{array}{lllll}\text { school years. Journal of Educational Psychology, 89, } & \text { 451-469. }\end{array}$ http://dx.doi.org/10.1037/0022-0663.89.3.451 
Wigfield, A., Hoa, L. W., \& Klauda, S. L. (2008). The role of achievement values in the Motivation and self-regulated learning. In Theory, research, and applications (pp. 169-195). New York: Erlbaum.

\section{Copyrights}

Copyright for this article is retained by the author(s), with first publication rights granted to the journal.

This is an open-access article distributed under the terms and conditions of the Creative Commons Attribution license (http://creativecommons.org/licenses/by/3.0/). 